\title{
Structural framework conditions and individual motivations for youth- mobility: A macro-micro level approach for different European country-types
}

Karen Hemming ${ }^{1, \neq}$, Tabea Schlimbach ${ }^{1}$, Frank Tilmann ${ }^{1}$, Birte Nienaber ${ }^{2}$, Monica Roman ${ }^{3}$, Jan Skrobanek $^{4}$

\begin{abstract}
European youth mobility seems to be fostering Europe's unequal pace of integration, which sees certain countries benefit at the expense of others (Ohmacht et al., 2009; van Mol \& Timmerman, 2014). Using a comparative approach, the paper aims to relate a macro-level country-typology focussing on human capital with individual mobility-motivations on the micro-level. Our methodological approach is based on a secondary macro-data analysis and analyses of mobility-motivations of young people (micro-data) deriving from qualitative $(N=152)$ and quantitative data $(N=5,499)$ collected in six European countries. In order to examine correspondence between macro-conditions and micro-aspects, we relate information on mobilitymotivations to the country-typology by allocating mobile youth to the respective types of their home country. The results show that the country-types compose different opportunity structures, which are reflected in individual motivations. Accordingly, different country-types can be seen as an example of the heterogeneity and inequality of European social and territorial mobility frames.
\end{abstract}

Keywords: European youth mobility; micro-macro level approach; human capital; mobility motivations; multiple methods.

\section{Introduction}

One of the characteristics of the European Union are the significant socioeconomic disparities between member countries (OECD, 2017). Youth mobility ${ }^{1}$ is widely discussed as a tool to overcome these disparities and to ensure the EU objectives of social and territorial cohesion. The right of free movement within the EU is a substantial aspect of the European integration (Panwinkler \& Schön, 2014: 514). Mobility is thought to function as a 'big equaliser' due to its role in homogenising the educational and labour market(s) within the EU (van der Velde, 2012: 120). However, intra-European youth mobility has an ambivalent character. Although it can be seen as a driving economic force and as a catalyser for equality, not all European countries benefit from mobility in equal measure (Hemming, Tillmann, Reissig et al., 2016: 140ff; Manafi, Marinescu, Roman \& Hemming, 2017). While some profit from mobility, others lose out in the competition for

\footnotetext{
¥ Corresponding author: Karen Hemming, German Youth Institute, Germany. E-mail: hemming@dji.de.

${ }^{1}$ German Youth Institute, ${ }^{2}$ University of Luxembourg, ${ }^{3}$ The Bucharest University of Economic Studies, ${ }^{4}$ University of Bergen.

${ }^{1}$ We use the term 'mobility' to refer to geographical cross-border movements of young people in Europe, regardless of their duration. The term includes in our understanding short-term and long-term geographical movements as well as permanent movements that are known as migration. In this way, we take into account the fact that new forms of intraEuropean migration have evolved in recent decades (Verwiebe, Teitzer \& Wiesbeck, 2014).
} 
human capital, especially when highly qualified youth move abroad on a long-term basis. Socioeconomic differences coupled with divergent development paths in actors' home and receiving countries are central features of contemporary European integration processes (Göler \& Köppen, 2015: 8). Thus, mobility and social inequalities in Europe can be regarded as mutually reinforcing (Amelina \& Vasilache, 2014), and this raises legitimate questions about the unequal shares of mobility costs and benefits at national level and its correspondence to individuals' motivations for becoming mobile.

Starting from common ground, one would assume a significant degree of correspondence between macro-level developments in the context of the European integration process, and individual actions on the micro-level (Blossfeld, Klijzing, Mills \& Kurz, 2005: 3). Departing from this assumption, we examine possible interlinkages between framework characteristics on the macro-level and individual modes of ${ }^{2}$ and motivations for mobility. A macro country-typology based on the unequal national allocation of mobility costs and benefits forms the starting point for this paper.

The paper ${ }^{3}$ aims to explore how country-type characteristics on the macro-level correspond with individual motivations for intra-European youth mobility and corresponding social inequalities. It furthermore addresses the question of whether individual modes of and motivations for mobility coincide with the identified country-types. A multiple methods design is used to scrutinise the interlinkage of macro conditions and individual motivations, comprising different empirical approaches.

\section{Theoretical background}

Intra-European youth mobility is one of the most vibrant characteristics of contemporary Europe, often perceived as strong premise for human capital creation and development (Acharya \& Leon-Gonzalez, 2014; Basilio, Bauer \& Kramer, 2017). From an economic perspective, human capital is defined as a set of skills that contributes to labour productivity and a capital in which workers make investments. Numerous explanations for the role of mobility in influencing human capital exist (e.g. Kan, 1999; Khwaja, 2002; Korpi \& Clark, 2017). According to Becker (1975), human capital is people's investment in their skills to maximise the net present value of future earnings - mobility is seen as a result of such an investment decision. However, mobility could also be seen as a means to invest in human capital (Sjaastad, 1962). Following both approaches, mobility effects human capital. Accordingly, one of the focuses of the macro-typology of European countries drawn up by the researchers is on student mobility, considered to be a clear investment in one's human capital. However, human capital is not necessarily perfectly portable and movers might face difficulties in adapting the skills that they acquired in their countries of origin to the new destination context (Friedberg, 2000).

For explaining modes of and motivations for mobility episodes of youth on micro-level, we start from life course theory (Elder, 1995: 47) assuming that young people act according to their life stage (Blossfeld et al., 2005; Brannen \& Nilsen, 2005; Hurrelmann \& Quenzel, 2013; Walther,

\footnotetext{
${ }^{2}$ By modes we understand fields of mobility e.g. employment mobility, student mobility, mobility within the context of vocational educational training (VET).

${ }^{3}$ The paper originates from the EU-project MOVE which has received funding from the EU-Horizon 2020 research and innovation programme under grant agreement No.649263. Parts of the paper are based on the following MOVE reports: Public Work Package Report WP2, Public Work Package Report WP4 (see www.move-project.eu/reportspublications/).
} 
2001). Depending on the availability of resources (Brannen \& Nilsen, 2005: 422) and lifeorientations, young people actively define the situation they live in and choose mobility opportunities that fit with their motivations, socioeconomic resources, and life-stage-specific structural constraints (Blossfeld et al., 2005: 2-4; Buchholz, Hofäcker, Mills, Blossfeld, Kurz \& Hofmeister, 2009: 55; Bynner, 2005; Dewild, 2003: 117; Elder, 1995; Walther, 2001). Hence, developing a specific motivation for mobility can be seen as a function of the young person's perception of the situation, personal characteristics, and the situational constraints the person lives under (Blossfeld et al., 2005: 2-4).

Three of the central developmental tasks during the transition from youth to adulthood are 'accumulating qualifications' and 'economic independence' as key preconditions for participating in 'consumption' (Buchholz et al., 2009: 56; Hurrelmann \& Quenzel, 2013: 263; Miles, 2000: 28). In our approach, the realisation of the 'tasks' - woven in modes of and motivations for mobility is bounded by given structures and frameworks within which young people act (Giddens, 1984). Consequently, we expect that the modes of and motivations for mobility among young people who grow up in regions with limited socioeconomic opportunity structures on the macro-level will be different from those among people who grow up in regions with a broader range of opportunities. We further assume that lifestyle related opportunity structures (Miles, 2000: 30-32) also play a role in becoming internationally mobile. The composition of both sides of the coin - the structural and lifestyle side - will bring about kinds of convergent or divergent modes and motivations that correspond with mobility-related country-specific opportunity structures represented by our country typology.

To sum up, we assume that individual (micro) motivations for and modes of mobility will vary according to unequal opportunity (macro) structures. Among those who have difficulties finding opportunities to secure their 'economic independence', economic, work-related, or financial issues will be the prevailing motivations for moving abroad. Conversely, having good educational/work prospects will make personal lifestyle-related motivations for mobility more likely. Additionally, we assume that social reasons are more often action guiding than solely work-related reasons (Verwiebe et al., 2014: 129). Thus, non-economic motivations can also act as powerful motivations for youth mobility (Cairns \& Smyth, 2010; Korpi \& Clark, 2017; Sirkeci \& Cohen, 2016).

\section{Methods}

In order to capture these different theoretical dimensions, more than one method is required. Consequently, the analysis is based on a multi-methods design (Hunter \& Brewer, 2015) combining macro analysis on the national level with individual qualitative and quantitative analysis of mobile youth in an explorative manner.

(1) The question of mobility-induced human capital flows was approached by means of a secondary data analysis on the macro-level which was based on a macro-data compilation (MOVESUF; Hemming, Tillmann \& Dettmer, 2016) set up with data for 31 European countries (EU-28, EFTA) for 10 years (2004-2013) using macro-data from Eurostat, the OECD, the UN, and the World Bank. The country-typology focuses on five youth mobility indicators: 1) short-term incoming youth mobility ( $<3$ years), 2) long-term incoming youth mobility ( $>3$ years), 3) short-term returning mobility (captures finished mobilities one year prior to data collection), 4) incoming studentmobility, and 5) outgoing student-mobility (Hemming, Tillmann, Reissig et al. 2016). To capture more recent developments (e.g. economic crisis) within the available database, the country typology concentrates on data from 2009-2013 only. 
(2) In order to capture the link between individual modes/motivations and macro level frameworks, analyses were made using micro-data from an online-survey which was conducted in six countries reflecting different macro-conditions for youth-mobility in Europe: Germany (DE), Hungary (HU), Luxembourg (LU), Norway (NO), Romania (RO), and Spain (ES) with mobile and non-mobile youth $(\mathrm{N}=5,499)$ aged 18-29 (Navarrete Moreno, Lorenzo-Rodriguez \& Diaz Chorne et al., 2017). Mobility modes were captured for each reported mobility while mobility motivations were captured in general using a multiple response set and were aggregated for the analysis on personal level. The data was analysed descriptively using frequencies for the indicators per country type.

(3) In order to approach individual motivational processes related to mobility experiences in the light of national opportunity structures, explorative interviews with mobile youth were analysed. The qualitative case study comprised different modes of mobility in the six above-mentioned countries. A total of $\mathrm{N}=152$ qualitative, problem-centred interviews (Witzel, 2000) were conducted with outgoing mobile youth aged 18-29. The analysis steps included initial computer-assisted thematic coding and the analysis of 'core themes' (Bernard, Wutich \& Ryan, 2017). For the purposes of this paper, cross-case comparisons (Cruzes, Dybå, Runeson \& Höst, 2015; Miles \& Huberman, 1984) of individual mobility motivations of young people representing different country-types have been conducted, considering codes related to mobility inducement and motivations.

\section{Macro country-typology as starting point}

Initially, the macro analysis was based on a heuristic causal mobility model (Tillmann, Skrobanek \& Hemming, 2016) providing a set of potentially relevant macro-indicators as causes for mobility and corresponding social inequalities of intra-European youth mobility in the sectors economy (labour market, prosperity; e.g. unemployment rate, GDP), state (education, welfare; e.g. language skills, GINI-index) and society (living conditions, demography; e.g. HDI, youth rate) (ibid.: 36). Subsequently, by using these indicators, a cluster analysis was conducted detecting centre-receiving countries and periphery-sending countries ${ }^{4}$ (Manafi et al., 2017) and pointing to the centre-periphery-dynamics (Wallerstein, 1974). The clusters revealed that youth mobility flows are affected by unequal socio-economic national framework conditions and, consequently, foster existing inequalities on the national level (Hemming, Tillmann \& Reißig et al., 2016).

However, the centre-periphery-model does not capture the full complexity of intra-European youth mobility. Thus, a country-typology focusing on the mobility-based creation and exploitation of human capital was developed based on two dimensions: 1) mobility episodes which mainly deploy/exploit human capital through long-term incoming youth mobility, outgoing studentmobility, or returning mobility, and 2) mobility episodes that to a great extent create human capital in the host countries in the form of short-term incoming youth mobility or incoming studentmobility. A combination of both dimensions resulted in a country-typology indicating whether and to what extent a country benefits from youth mobility flows in Europe. Each country was allocated

${ }^{4}$ As centre receiving countries were identified DE, FI, SE, UK, IE, DK, NL, BE, FR, IT, AT. As periphery sending countries were identified PT, ES, HR, PL, CZ, HR, GR, EE, LV, LT, SK, HU, RO, BG, SL, CY, MT (https://ec.europa.eu/eurostat/statistics-explained/index.php/Glossary:Country_codes). 
manually to one of the four types, depending on the median scores of each included mobility indicator per year for 2009-2013 (Table 1, Figure 1).

Table 1: Country-typology of youth mobility in Europe (Hemming, Tillmann \& Reißig et al., 2016: 141)

\begin{tabular}{|c|c|c|c|}
\hline \multirow{2}{*}{\multicolumn{2}{|c|}{$\begin{array}{c}\text { Country-typology on youth } \\
\text { mobility }\end{array}$}} & \multicolumn{2}{|c|}{$\begin{array}{l}\text { Human capital creation } \\
\text { oming mobility } \\
\text { ent-mobility }\end{array}$} \\
\hline & & Low & High \\
\hline \multirow[t]{2}{*}{$\begin{array}{r}\text { Human capital } \\
\text { deployment/ } \\
\text { exploitation } \\
\text { - } \text { long-term youth } \\
\text { mobility } \\
-\quad \text { returning mobility } \\
-\quad \text { outgoing student } \\
\text { mobility }\end{array}$} & Low & $\begin{array}{l}\text { Mobility Promoters } \\
\text { - } \quad \text { Poland, Romania, Slovenia, } \\
\text { Finland, Bulgaria } \downarrow \text {, Slovakia } \downarrow \text {, } \\
\text { Hungary, Malta, Italy } \downarrow \\
\text { - } \quad \text { mainly from Eastern Europe } \\
\text { - low rate of human capital creation } \\
\text { by hosting mostly foreign short-term } \\
\text { mobile youth and human capital } \\
\text { deployment by sending youth for long- } \\
\text { term studying abroad } \\
\text { - unfavourable economic conditions } \\
\text { push young people abroad }\end{array}$ & $\begin{array}{l}\text { Mobility Fallers } \\
\text { Czech Republic, Netherlands, Belgium, } \\
\text { Sweden } \downarrow \\
\bullet \quad \text { comparably small group of countries } \\
\text { - combines low rate of incoming long- } \\
\text { term mobilities / returning mobilities with } \\
\text { high rate of short-term incoming mobilities } \\
\bullet \quad \text { countries spend more resources for } \\
\text { the education of foreign students, but do } \\
\text { not appropriately profit from created } \\
\text { human capital }\end{array}$ \\
\hline & High & $\begin{array}{l}\text { Mobility Beneficiaries } \\
\text { Latvia, France } \rightarrow \text {, Estonia, Greece } \uparrow, \\
\text { Spain } \uparrow \text {, Portugal } \uparrow \text {, Croatia } \\
\text { • countries are less involved in } \\
\text { human capital creation } \\
\text { - deploying of long-term mobility } \\
\text { and education from other countries with } \\
\text { high rates of returning / outgoing } \\
\text { student-mobility } \\
\text { - compared to the other types those } \\
\text { countries benefit most from youth } \\
\text { mobility flows within Europe }\end{array}$ & $\begin{array}{l}\text { Mobility Utilisers } \\
\text { Ireland, Norway, Germany, Cyprus, } \\
\text { Denmark, UK, Luxembourg, Austria } \\
\text { - } \quad \text { balanced proportion of long-term } \\
\text { incoming / short-term incoming youth } \\
\text { - } \quad \text { high ratio of in- and outgoing } \\
\text { student-mobility and returning mobility } \\
\text { - countries belong to the prospering } \\
\text { centre-receiving cluster } \\
\text { - utilise youth mobility for human } \\
\text { capital creation and usage }\end{array}$ \\
\hline \multicolumn{4}{|c|}{$\begin{array}{l}\rightarrow \uparrow \text { The arrows indicate a changing tendency towards another mobility type, e.g. Greece, Spain, and Portugal exhibit a recent } \\
\text { tendency towards mobility promoters. } \\
\text { Indefinite countries due to lacking data: Lithuania, Iceland, Switzerland }\end{array}$} \\
\hline
\end{tabular}

When linking the country typology to our heuristic model (Tillmann et al., 2016), each type serves as a proxy for different socioeconomic country specific-characteristics presented in Tab. 2 and reflects manifold socioeconomic disparities. A combination of both enabled assumptions for corresponding links to the micro level (see above). In order to analyse these assumptions, individual modes of and motivations for mobility deriving from the online survey in six European countries are combined with the country types. Consequently, the following micro analysis is based on six country cases, which are allocated to three of the four country types (Table 2$)^{6}$.

${ }^{5}$ Eight countries could not be allocated to one type unambiguously or showed a changing characteristic towards a different type (Hemming, Tillmann \& Reißig et al., 2016: 140-143).

${ }^{6}$ Caused by the sample composition, no mobility faller country was represented in the overall research project. 
Figure 1: Allocation of countries to typology of intra-European youth mobility (own source)

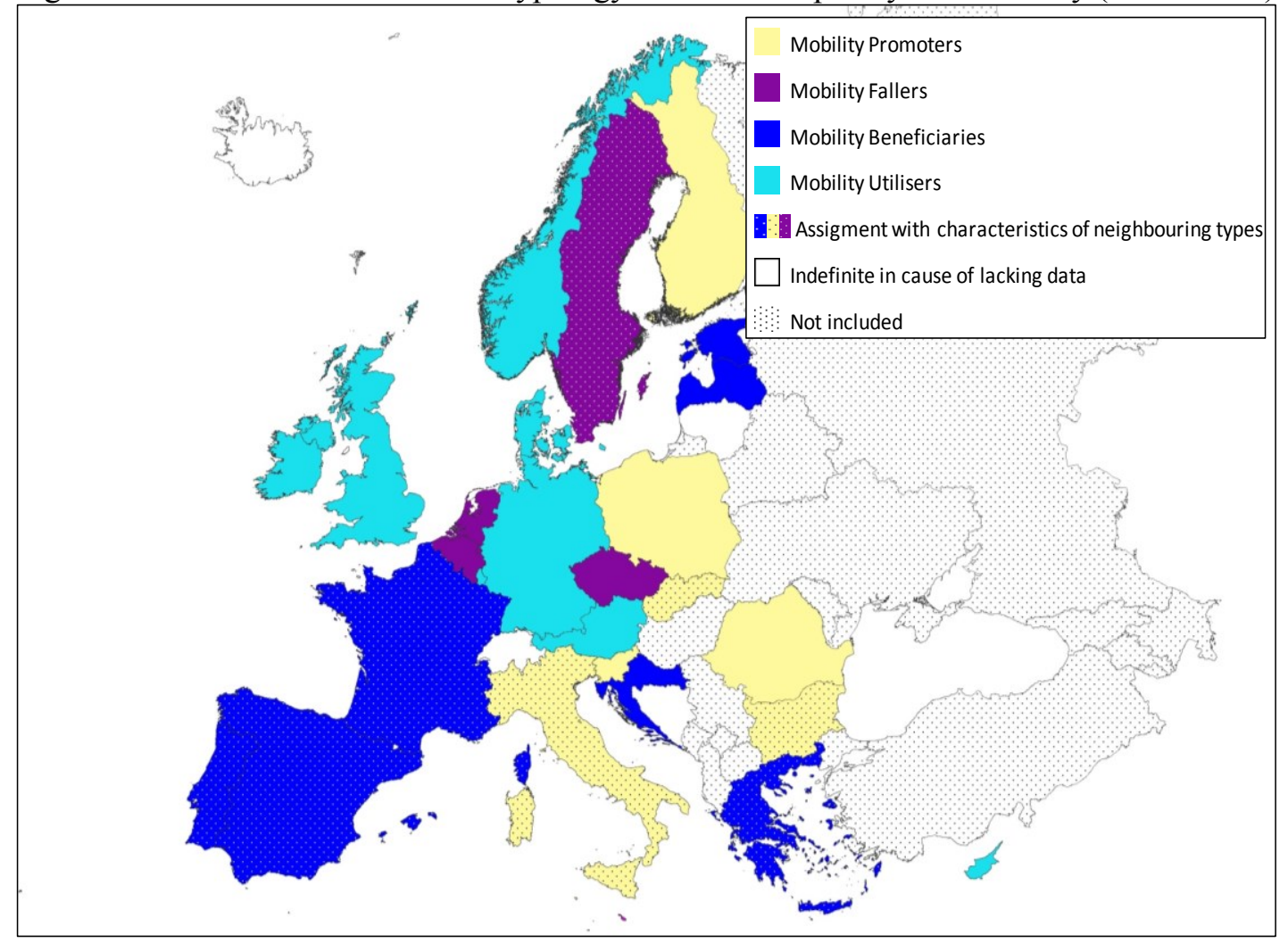

Table 2: Country characteristics of the included sample countries

\begin{tabular}{|c|c|}
\hline Country-type & Characteristic comparisons between the six sample countries \\
\hline $\begin{array}{rr}\text { Mobility promoters } \\
\checkmark & \text { Hungary } \\
\checkmark & \text { Romania }\end{array}$ & $\begin{array}{ll}- & \text { comparatively weak economies (lowest GDP, lowest wages) } \\
- & \text { tense labour markets (higher (youth-) unemployment, higher NEET rate) } \\
\text { - } & \text { comparatively weak welfare system (lowest expenditures on social protection) } \\
- & \text { varying living standards (HU=high HDI, RO=low HDI) } \\
- & \text { lower social inequality (lower GINI index), however comparatively highest } \\
& \text { poverty rates } \\
\text { - } & \text { decreasing but still higher ratio of youth in society } \\
\text { - } & \text { lowest levels of foreign population }\end{array}$ \\
\hline $\begin{array}{c}\text { Mobility beneficiaries } \\
\checkmark \text { Spain }\end{array}$ & $\begin{array}{ll}- & \text { slowly growing economies (lower GDP, lower wages) } \\
- & \text { tense labour markets (highest (youth-) unemployment, highest NEET rate) } \\
- & \text { comparatively low welfare situation (lowest HDI) } \\
- & \text { high social inequality (highest GINI index), high poverty } \\
- & \text { decreasing youth share, lowest ratio of youth in society } \\
- & \text { high level of foreign population }\end{array}$ \\
\hline $\begin{aligned} & \text { Mobility utilisers } \\
& \checkmark \text { Germany } \\
& \checkmark \text { Luxembourg } \\
& \checkmark \text { Norway }\end{aligned}$ & $\begin{array}{ll}- & \text { comparatively strong economies (rising GDP, rising wages) } \\
\text { - } & \text { labour markets: low (youth-) unemployment, low NEET rate } \\
\text { - } & \text { high living standards (high HDI) } \\
\text { - } & \text { varying social inequality (NO=lowest GINI, LU\&DE= high GINI), lower poverty } \\
- & \text { comparably stable, medium-sized ratio of youth in society } \\
- & \text { high level of foreign population (especially LU) }\end{array}$ \\
\hline
\end{tabular}




\section{Accounting modes of and motivations for mobility on the micro-level: quantitative approach}

Based on the macro-typology the online-survey micro-data was analysed to identify similarities and differences in modes of and motivations for mobility for three of the four countrytypes. Therefore, the respondents were classified according to their country of origin to youth from: promoter countries (HU, RO; $n=1,938)$, beneficiary countries $(E S ; n=780)$, utiliser countries (DE, $\mathrm{LU}, \mathrm{NO} ; \mathrm{n}=2,781$ ). The dataset was weighted for age, gender, and level of education (Navarrete Moreno et al., 2017: 24f).

The modes for mobility differ mainly between youth from promoter countries and those from utiliser countries (Figure 2). The differences are visible especially for educational mobilities (students, VET, pupils) and working mobilities but less in au-pair/voluntary mobilities: Youth from utiliser countries exhibit higher rates of educational mobilities whereas youth from promoter countries tend to leave the country more often for working mobilities, reflecting disparities in human capital movements. Furthermore, the total mobility rate affirms characteristics of the country-types with youth from promoter countries having lower outgoing mobility rates than those from utiliser countries. However, the only beneficiary country Spain exhibits tendencies towards both of the other types, illustrating its changing characteristic towards the mobility fallers due to the impacts of the economic crisis since 2008.

Figure 2: Mobility-modes (percentage of mobile and non-mobile youth)

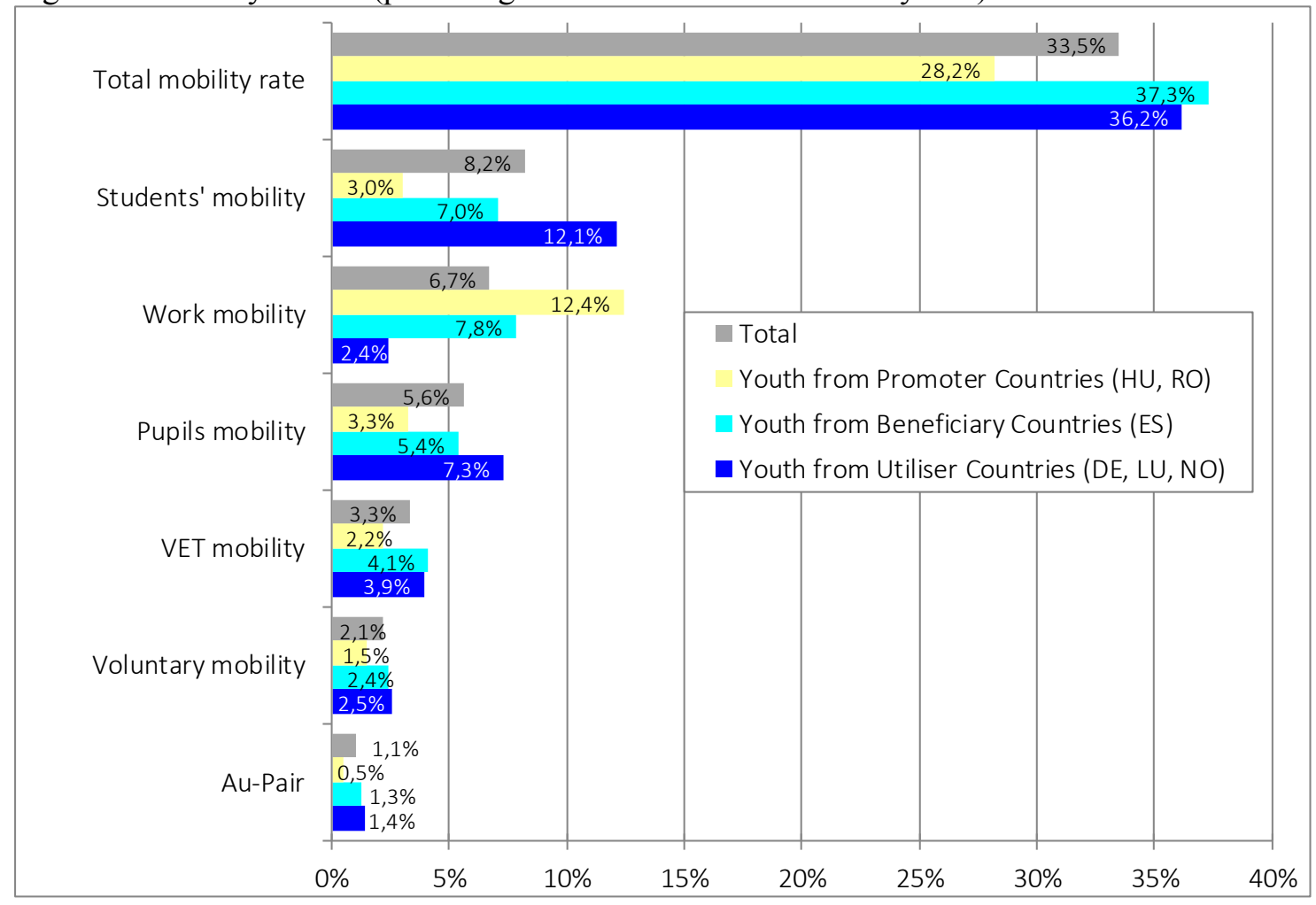




\section{Structural framework conditions and individual motivations for youth-mobility}

For the analysis of mobility motivations, only respondents with mobility experiences were included $(n=1,843)$ and allocated to youth from: promoter countries $(n=546)$, beneficiary countries $(\mathrm{n}=291)$, utiliser countries $(\mathrm{n}=1,006)$. The captured motivations cover educational and personal motivations as well as motivations driven by personal prerequisites and perceived socioeconomic constraints in the home country. ${ }^{7}$ According to the modes, mobility motivations differ mainly between youth from promoter countries and those from utiliser countries (Figure 3). Again, the mobility-motivations of Spanish youth show characteristics of both other country types. The greatest difference could be found in the perceived socioeconomic constraints in the home country, matching the macro-types and corresponding socioeconomic disparities: Youth from promoter countries are more likely to be pushed to move abroad because of poor working conditions and tense labour markets, lowering their chance of finding a suitable job. Besides, the political situation in their countries tends to push more youth abroad - pointing to the still problematic political situation in the post-socialist countries Romania and Hungary. According to our assumption, differences in personal motivations are less pronounced. The main mobility motivations for youth from utiliser countries lie in the educational sector, according to higher rates of educational mobility in utiliser countries. Spanish youth, however, have the highest motivation to learn the language of the destination country, pointing to persisting deficits in foreign language acquisition.

\section{Accounting modes of and motivations for mobility on the micro-level: qualitative approach}

The results of the quantitative survey indicate that macro mobility contexts radiate onto the level of individual mobility motivations and linked inequalities. However, they cannot tell us about drivers behind these motivations. The complementary analysis of qualitative material was helpful both as a means of further validating and discussing the survey results and of gaining a deeper understanding of individual interpretations. Questioning whether national economic contexts condense in young people's mobility scopes, we analysed individual mobility motivations of young people from different country types based on qualitative interviews with outgoing mobile young people. The results will be illustrated alongside the country-types.

Amongst youth from utiliser countries, in line with the survey results, motivations for going abroad related to financial and vocational improvement were less relevant than for youth from promoter countries. Moreover, they less often articulated in comparison with other motivations for this group. It seems that while these young people were made aware of, and confirmed work-related advantages of mobilities when explicitly asked, they were less relevant for conscious decisions according to the explorative questioning in the interviews. Instead, drivers related to personal development featured most prominently in the qualitative data, including curiosity for foreign cultures and people, as well as the idea of gaining new experiences, becoming independent and growing up. Aside from this, we discovered another underlying driving force that was prominent among youth living in the prosperous economic utiliser countries and which can be defined under the concept of convenience (Reiter \& Schlimbach, 2015). Many of the young simply took the opportunity to become mobile, e.g. by following the encouragement of friends or mobility

\footnotetext{
${ }^{7}$ Educational motivations: learning the language, studies, personal/professional development. Personal motivations: love, family related reasons, personal relationships, personal health, feeling attracted to the culture. Personal preconditions: having been there before, previous knowledge of the language. Socioeconomic constraints in home country: improving of work conditions, financial situation in home country, unable to find a job, political situation in home country.
} 
promoting institutional actors, and did so because it involved only little own effort and low risk and insecurity:

"I think if Mrs. Grünwald hadn't made such an effort: 'Yeah, just do it!' and I think if the employer had not said 'Yeah no problem, we will help pay for it' my decision may have been very different." (vcDEy01, 169; German VET-student moving to UK)

Figure 3: Motivations for becoming mobile (percentage of mobile youth)

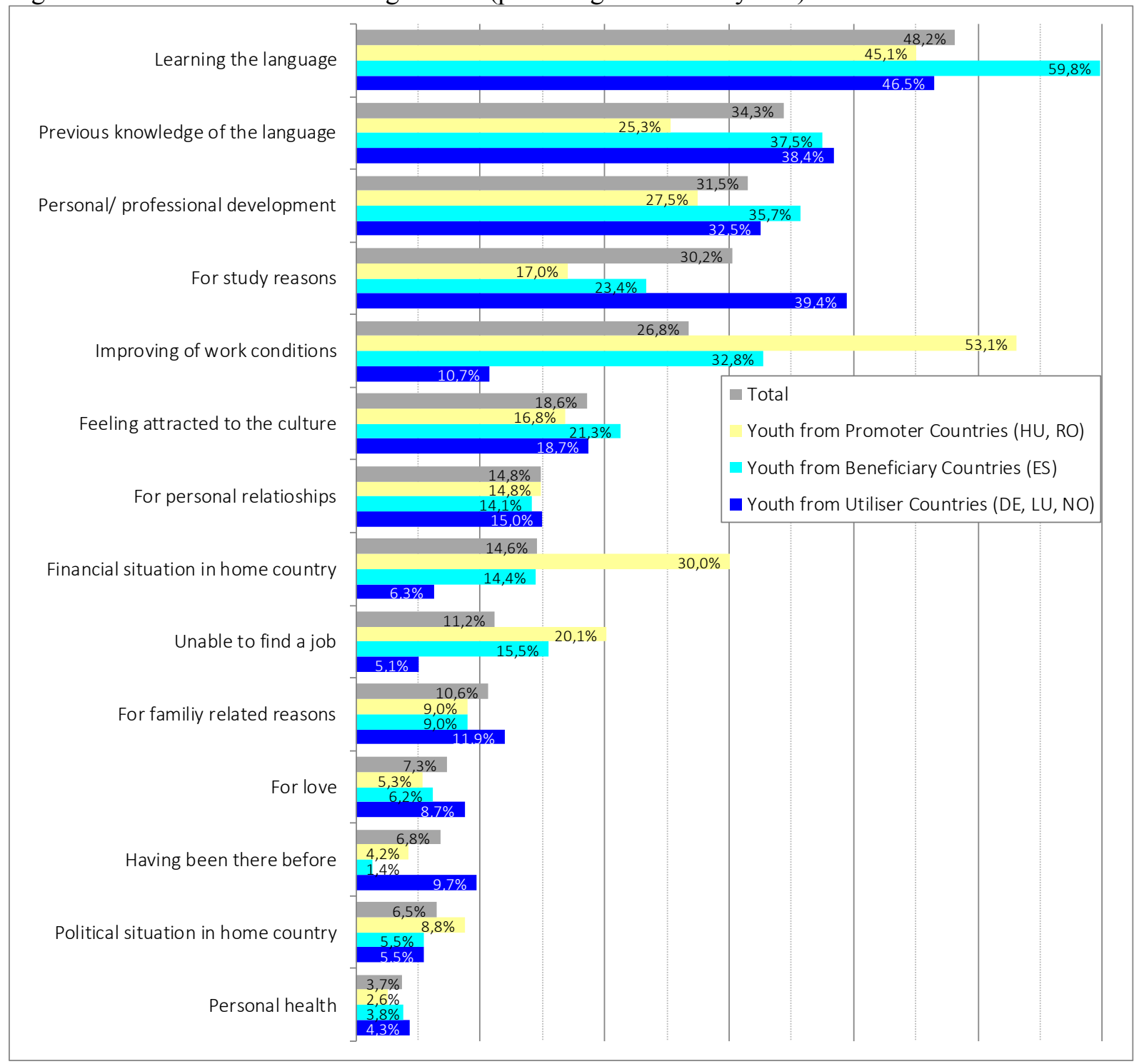

Analogous to the survey results, young people from Hungary and Romania (coming from promoter countries), often perceive mobility as an opportunity to escape the unfavourable economic situation in their home countries. They aim at life improvement (better living conditions, higher salaries) and professional development: 
"I started a business in agriculture and I wanted to go and do a training course. [...] I went there and I learned about a business in agriculture. I went to specialise." (enROy09, 2; Romanian entrepreneur in Italy)

They also want to set themselves apart from non-mobiles in their countries. However, cultural curiosity and adventuresomeness, while quantitatively less visible, are important motivations also among this group. Other motivations that appear stronger in qualitative data include fulfilling a family mandate by going abroad (by following the expectations of parents) or following the example of mobile friends.

In our country sample, the only representative for beneficiary countries is Spain - showing a tendency towards becoming a mobility promoter country. While this might limit the expressiveness regarding motivations of youth from beneficiary countries, the similarities both to motivations of young people from promoter countries and to those from utiliser countries reflect the transformative situation of Spain between different country types on the macro-level. Just like Hungarians and Romanians, Spanish young people place emphasis on competency enhancement and exploring new/better labour market opportunities abroad. Becoming mobile offers a career advantage over their non-mobile peers. However, similar to young people from utiliser countries, they are also interested in alternative life and working cultures and have a strong sense of mobility as an opportunity to mature. Moreover, the data indicates a high motivation to increase language competencies among Spanish young people in comparison with young people from other countries:

"Being able to live abroad is something that has always caught my attention. And the

fact of knowing how they worked elsewhere than Spain [...]. And the fact to improve my language and to meet other people and another culture." (vcESy03, 55; Spanish VET-student who moved to Malta)

We also discovered variances across modes of mobility and countries, which cannot be excluded from the discussion. For example, for many students from Luxembourg, going abroad is perceived as 'youth normative', since it is an obligatory part of their studies (Kmiotek-Meier \& Karl, 2017). For German VET-students, motivations that are directed to learning and vocational improvement (such as language learning) did not dominate the decisions to become mobile which might be traced back to the fact that they did not feel a 'biographical need' to move due to their stable vocational situation and positive career prospects.

\section{Discussion and synthesis of the results}

The analysis of modes of mobility supports the human capital approach, which was applied by the country-typology: Mobility-promoter countries hardly profit from human capital movements with their low rate of educational mobilities, whereas utiliser countries make use of the manifold opportunities for outgoing educational mobility and, in so doing, gain and exploit human capital (Clemens, 2007). Consequently, the results indicate asymmetric patterns of human capital movements in the context of intra-European youth mobility evolving especially through sustainable inequalities on the national level between centre-receiving and periphery-sending countries (Manafi et al., 2017). Accordingly, our results confirm that youth mobility and social disparities underlie reciprocal reinforcing effects (Amelina \& Vasilache, 2014; Göler \& Köppen, 2015).

Additionally, the results are in line with macro-economic 'brain drain' perspectives (Baláz, Williams \& Kollár, 2004; Docquier \& Rapoport, 2012; Dodani \& Laporte, 2005) since long-term outflows of human capital often lead to a 'brain drain', and, conversely, inflows of human capital to a 'brain gain' (Tung \& Lazarova, 2007). Both terms are used to account for inequalities generated 
by human capital redistribution within Europe, while depicting on the one hand the costs of migration as a loss of skilled labour for the sending countries and, on the other hand, benefits for receiving countries. However as mobility includes moving back to the sending country/another country, the term 'brain circulation' (Smoliner, Förschner, Hochgerner \& Nová, 2013) can also be adapted being especially important for central and eastern European countries.

The micro-results of the survey on modes of and motivations for mobility allow a more differentiated perspective on the motivations behind youth mobility, adding an individual perspective to the unequal socioeconomic structural conditions on the macro level. Thus, the country types offer different lifestyle related opportunity structures (Miles, 2000) and structural frameworks (Giddens, 1984) for varying modes of and motivations for mobility on micro level. Mobile youth from promoter countries focus on escaping unfavourable socioeconomic conditions in their home countries (Kazlauskiene \& Rinkevicius, 2015) taking with them human capital from which their countries of destination can profit, while youth from utiliser countries are rather driven by personal and educational motivations and, upon return, acquire human capital for the benefit of their countries of origin.

The results of the qualitative research also reinforce the concept of the country typology and bear witness to individual reflectiveness of, and creative responsiveness to nation-specific opportunity structures (Miles, 2000). They show that mobilities are used by young people as strategies to increase their human capital, and as instruments to enhance their personal life situation as well as to exploit the capacities of European labour markets in favour of their educational and vocational transitions (Hurrelmann \& Quenzel, 2013). However, they also provide a deeper insight into the drivers behind mobility decisions and, amongst others, the role of 'taking the chance' instead of purposeful planning of mobilities. Still, while possibilities for young people depend on nation-specific options (Elder, 1985: 44), young mobiles extend their latitudes through mobilities.

At the same time, our comparative research in both empirical micro approaches confirms the existence of powerful non-economic motivations for the observed youth (Cairns \& Smyth, 2010; Korpi \& Clark, 2017; Verwiebe et al., 2014) and the variation of motivations across different educational/biographical settings in which mobilities are embedded (see also Schlimbach, Skrobanek, Kmiotek-Meier \& Vysotskaya, this issue).

\section{Conclusions, limitations, and future prospects}

Our comparative analysis presents different country types as an example of the heterogeneity and inequality of European social and territorial mobility frames. It further underlines the fruitfulness of integrated theoretical and empirical approaches, which combine different levels of analysis - in our case macro and micro data - for analysing young people's modes of mobilities and motivational frames when moving internationally. It thus gives evidence to a broader European perspective and policies, which promote social and economic equality across Europe (Evers, 2008: 304).

The results of the country typology emphasise the positive and negative effects of different mobility flows within Europe, where some countries profit from long-term incoming mobility offering better socioeconomic framework conditions whereas others lose their qualified young people due to prevailing poor conditions regarding employment and living. This trend leads to 'selfenergising' effects, which increase disparities between European states. It also shows a dynamism in this typology where some countries show changing characteristics (e.g. because of the economic crises). Thereby, the promoter countries are worse off since they have the poorest socioeconomic framework conditions: They tend neither to invest nor to make use of human capital creation and 
are therefore faced with a twofold exploitation. In general, it is important to find appropriate measures in favour of a more balanced distribution of costs and benefits of mobility among European states. According to Deas and Hincks (2014: 2580), one of the main challenges for the European territorial cohesion is to find a way of retaining the socioeconomic benefits of mobility whilst at the same time dealing with its described negative side effects.

Not least, the consideration of qualitative material helped to gain a deeper understanding of youth motivations. For once, it shed light on how young people reflect, and respond to, the economic situation of sending and destination countries. At the same time, it revealed influential noneconomic motivations that are rooted in their personal and vocational situation and in opportunity structures.

Despite the complexity of our presented research, we dealt with some limitations:

(1) When compiling the database for the macro-analysis (Hemming, Tillmann \& Dettmer, 2016), the available macro-data for European youth-mobility flows was comparably old (even though the lasted years of observation were used, most recent datasets were only from 2013).

(2) Mobility faller countries were not included in the overall design of the study, so the analysis on the micro-level could only focus on three of the four country-types. Nevertheless, the typology characteristics suggest that faller countries might face a continuous loss of resources, mainly through the imbalance regarding incoming and outgoing mobilities and linked disproportional investments in human capital.

(3) Institutions and networks play a central role in understanding mobility insofar as they filter macro-events and/or structural conditions and bridge young people's motivations with opportunity structures (Blossfeld et al., 2005). However, due to research-economic reasons the strategy of the paper did not include the meso-level perspective in the analysis.

(4) As we focussed on mobile young people, we analysed only those who overcame the barriers for mobility even though it might have affected their mobility choice. More on hindering factors can be found in Kmiotek-Meier, Skrobanek, Nienaber et al. (2019).

Taking these limitations as a challenge, they could be faced in future research, e.g. by capturing and providing more recent macro-data on European youth mobility, replicating the study with individual data from all country-types, including meso-level characteristics, and last but not least focusing on the analysis of barriers to mobility and thereby producing a more realistic picture of European youth mobility.

\section{References}

Acharya, C. P. and Leon-Gonzalez, R. (2014). "How do migration and remittances affect human capital investment? The effects of relaxing information and liquidity constraints". Journal of Development Studies, 50 (3): 444-460. https://doi.org/10.1080/00220388.2013.866224

Amelina, A. and Vasilache, A., 2014. "The shadows of enlargement: Theorising mobility and inequality in a changing Europe", Migration Letters, 11 (2): 109-124. https://doi.org/10.33182/ml.v11i2.233

Baláz, V., Williams, A. M. and Kollár, D. (2004). "Temporary versus permanent youth brain drain: Economic implications", International Migration, 42 (2): 3-34. https://doi.org/10.1111/j.0020-7985.2004.00293.x

Basilio, L., Bauer, T. K. and Kramer, A. (2017). "Transferability of human capital and immigrant assimilation: An analysis for Germany", Labour, 31 (3), 245-264. https://doi.org/10.1111/labr.12096

Becker, G. (1975). Human capital (2nd ed.). Chicago: University of Chicago Press.

Bernard, H. R., Wutich, A. and Ryan, G. W. (2017). Analyzing qualitative data. Systematic approaches. Los Angeles: Sage. 
Blossfeld, H.-P., Klijzing, E., Mills, M. and Kurz, K. (2005). Globalization, uncertainty and youth in society. London: Routledge.

Brannen, J. and Nilsen, A. (2005). "Individualisation, choice and structure: a discussion of current trends in sociological analysis", The Sociological Review, 53 (3): 412-428. DOI: 10.1111/j.1467954X.2005.00559.x.

Buchholz, S., Hofäcker, D., Mills, M., Blossfeld, H-P., Kurz, K. and Hofmeister, H. (2009). "Life Courses in the Globalization Process: The Development of Social Inequalities in Modern Societies", European Sociological Review, 25 (1): 53-71. https://doi.org/10.1093/esr/jcn033

Bynner, J. (2005). "Rethinking the Youth Phase of the Life-course: The Case for Emerging Adulthood?", Journal of Youth Studies, 8 (4): 367-384. https://doi.org/10.1080/13676260500431628

Cairns, D. and Smyth, J. (2010). "Youth on the move? Student mobility and immobility in Portugal and Northern Ireland". In: D. Cairns (ed.): Youth on the move: European youth and geographical mobility, 59-70. Wiesbaden: VS. https://doi.org/10.1007/978-3-531-92331-4_6

Clemens, M. (2007). "Do Visas Kill?", Working Paper, 114: Centre for Global Development.

Cruzes, D. S., Dybå, T., Runeson, P. and Höst, M. (2015). "Case studies synthesis. A thematic, cross-case, and narrative synthesis worked example", Empirical Software Engineering, 20 (6): 1634-1665. https://doi.org/10.1007/s10664-014-9326-8

Deas, I. and Hincks, S. (2014). "Migration, Mobility and the Role of European Cities and Regions in Redistributing Population", European Planning Studies, $22 \quad$ (12): 2561-2583. https://doi.org/10.1080/09654313.2013.847062

Dewild, C. (2003). "A life-course perspective on social exclusion and poverty", British Journal of Sociology, 54 (1): 109-128. https://doi.org/10.1080/0007131032000045923

Docquier, F. and Rapoport, H. (2012). "Globalization, Brain Drain, and Development", Journal of Economic Literature, 50 (3): 681-730. https://doi.org/10.1257/jel.50.3.681

Dodani, S. and Laporte, R. E. (2005). "Brain drain from developing countries: how can brain drain be converted into wisdom gain?", Journal of the Royal Society of Medicine, 98 (11): 487-91. https://doi.org/10.1177/014107680509801107

Elder, G. H. (1985). "Perspectives on the life course". In: G. H. Elder (ed.) Life course dynamics: trajectories and transitions, 1968-1980: 23-49. New York: Cornell University Press.

Elder, G. H. (1995). "Life Trajectories in Changing Societies". In: A. Bandura (ed.) Self-Efficacy in Changing Societies, 46-68. Cambridge: Cambridge University Press. https://doi.org/10.1017/CBO9780511527692.004

Evers, D. (2008). "Reflections on territorial cohesion and European Spatial Planning", Tijdschrift voor Economische en Sociale Geografie, 99 (3): 303-315. https://doi.org/10.1111/j.1467-9663.2008.00463.x

Friedberg R. M. (2000). "You can't take it with you? Immigrant assimilation and the portability of human capital", Journal of Labor Economics, 18 (2): 221-251. https://doi.org/10.1086/209957

Giddens, A. (1984). The Constitution of Society. Berkeley and Los Angeles. University of California Press.

Göler, D. and Köppen, B. (2015). "Gastarbeiter reloaded? Anmerkungen zur EU-Binnenwanderung in der Schuldenkrise. Ein Editorial", Berichte. Geographie und Landeskunde, 89 (1): 5-11.

Hemming, K., Tillmann, F. and Dettmer, M. (2016). Users' manual for D2.5 MOVE-Scientific Youth File (SUF): Youth mobility macro data for Europe. Part of the MOVE-project: Mapping mobility - pathways, institutions and structural effects of youth mobility. Public Report. Halle (Saale): DJI. Available at: http://move-project.eu/reports-publications/ Database: http://dx.doi.org/10.7802/1653

Hemming, K., Tillmann, F., Reissig, B., Dabasi-Halász, Z., Nandori, E. S., Ilyés, C., Manafi, I., Marinescu, D. and Roman, M. (2016). "Conclusions and policy recommendations drawn out of the secondary macroanalysis in work package 2." In: K. Hemming, F. Tillmann and B. Reissig (eds.) Final Work Package Report WP2 "Sampling and secondary analyses of macro data of youth mobility in Europe and the partner countries". Part of the MOVE-project "Mapping mobility - pathways, institutions and structural effects of youth mobility". Public Report: 138-147. Halle (Saale): DJI. Available at: http://moveproject.eu/reports-publications/ 


\section{Structural framework conditions and individual motivations for youth-mobility}

Hunter, A. and Brewer, J. (2015). "Designing multi method research". In: S. Hesse-Biber and R. B. Johnson (eds.) Oxford handbook of mixed method and multi-method research: 185-205. Oxford: Oxford University Press.

Hurrelmann, K. and Quenzel, G. (2013) "Lost in transition: status insecurity and inconsistency as hallmarks of modern adolescence", International Journal of Adolescence and Youth, 18 (5): 1-10.

Kan, K. (1999). "Expected and unexpected residential mobility", Journal of Urban Economics, 45: 72-96. https://doi.org/10.1006/juec.1998.2082

Kazlauskiene, A. and Rinkevicius, L. (2015). "Lithuanian "brain drain" causes: Push and pull factors", Engineering economics, 46 (1): 27-37.

Khwaja, Y. (2002). "Should I stay or should I go? Migration under uncertainty: a real options approach", Department of Economics and Finance Research Discussion Papers. Brunel University, 02-10: 1-32.

Kmiotek-Meier, E. and Karl, U. (2017). "Being forced? Getting far? Speaking the language? What matters in the process of going abroad as a student?", Tér És Társadalom [Space and Society], 31 (4): 90-104. https://doi.org/10.17649/TET.31.4.2889

Kmiotek-Meier, E., Skrobanek, J., Nienaber, B., Vysotskaya, V., Samuk, S., Ardic, T., Pavlova, I., DabasiHalázs, Z., Diaz, C., Bissinger, J., Schlimbach, T. and Horvath, K. (2019). "Why is it so hard? And for whom? Obstacles in the intra-EU mobility", Migration Letters, 16(1): 31-44. https://doi.org/10.33182/ml.v16i1.627

Manafi, I., Marinescu, D., Roman, M. and Hemming, K. (2017). "Mobility in Europe: Recent Trends from a Cluster Analysis", Amfiteatru Economic, 46 (19): 711-726.

Miles, M. B. and Huberman, A. M. (1984). Qualitative data analysis. A sourcebook of new methods. Beverly Hills: Sage Publ.

Miles, S. (2000). Youth Lifestyles in a changing world. Philadelphia: Open University Press.

Navarrete Moreno L., Lorenzo-Rodriguez, J., Diaz Chorne, L., Diaz Catalan, C., Suarez-Lledo, V., Fernandez Araiz, V., Cuenca Garcia, C., Pallares i Cardona, E., Zuniga, R., de Luxan, A., Skrobanek, J., KmiotekMeier, E., Hemming, K., Tillman, F., Manafi, I. and Marinescu, D. (2017). Deliverable D.4.7 - Public Work Package 4 Report. Part of the MOVE-project: Mapping mobility - pathways, institutions and structural effects of youth mobility. Public Report. Madrid: ICN. Available at: http://moveproject.eu/reports-publications/

OECD (2017). Understanding the socio-economic divide in Europe. Background report. Available at https://www.oecd.org/els/soc/cope-divide-europe-2017-background-report.pdf

Ohnmacht, T., Maksim, H. and Bergman, M. M. (2009). Mobilities and Inequalities. Farnham: Ashgate.

Panwinkler, T. and Schön, K. P. (2014). "Freizügigkeit und Migration in der EU", Informationen zur Raumentwicklung, 6: 497-516.

Reiter, H. and Schlimbach, T. (2015). "NEET in disguise? Rival narratives in troubled youth transitions", Educational Research, 57 (2): 133-150. https://doi.org/10.1080/00131881.2015.1030851

Schlimbach, T., Skrobanek, J., Kmiotek-Meier, E. and Vysotskaya, V. (2019). "Capturing agency. A comparative approach to youth perceptions on mobility framing structures", Migration Letters, 16(1): 1529. https://doi.org/10.33182/ml.v16i1.635

Sirkeci, I. and Cohen, J. (2016). "Cultures of Migration and Conflict in Contemporary Human Mobility in Turkey", European Review, 24 (3): 381-396. https://doi.org/10.1017/S1062798716000119

Sjaastad, L. (1962). "The costs and returns of human migration", Journal of Political Economy, 70: 80-93. https://doi.org/10.1086/258726

Smoliner, S., Förschner, M., Hochgerner, J. and Nová, J. (2013). "Comparative Report on Re-Migration Trends in Central and Eastern Europe", In: T. Lang (ed.): Return Migration in Central Europe: Current trends and an analysis of policies supporting returning migrants. IfL Forum 21: 11-57. Leipzig: LeibnizInstitut für Länderkunde.

Tillmann, F., Skrobanek, J. and Hemming, K. (2016). "Heuristic causal mobility model based on macroindicators", In K. Hemming, F. Tillmann and B. Reißig (eds.) Final Work Package Report WP2 "Sampling and secondary analyses of macro data of youth mobility in Europe and the partner countries". Part of the 
MOVE-project "Mapping mobility - pathways, institutions and structural effects of youth mobility": 35 38. Public Report. Halle (Saale): DJI. Available at: http://move-project.eu/reports-publications/

Tung, R. L. and Lazarova, M. (2007). "Brain drain versus brain gain: an exploratory study of ex-host country nationals in Central and East Europe", The International Journal of Human Resource Management, 17 (11): 1853-1872. DOI: 10.1080/09585190600999992.

Van der Velde, M. (2012). "Boring European Borders?! Integration and Mobility across Borders", Eurasia Border Review, 3 (1): 115-125.

Van Mol, C. and Timmerman, C. (2014). "Should I Stay or Should I Go? An Analysis of the Determinants of Intra-European Student Mobility". Population, Space and Place, 20 (5): 465-479. https://doi.org/10.1002/psp.1833

Verwiebe, R., Teitzer, R. and Wiesbeck, L. (2014). "New forms of intra-European migration, labour market dynamics and social inequality in Europe", Migration Letters, 11 (2): 125-136. https://doi.org/10.33182/ml.v11i2.234

Wallerstein, I. (1974). The modern world system. Capitalist agriculture and the origins of the European world economy in the Sixteenth century. New York: Academic Press.

Walther, A. 2001. "Misleading trajectories: Transition dilemmas of young adults in Europe", Journal of Youth Studies, 4 (1): 101-118. https://doi.org/10.1080/13676260120028574

Witzel, A. (2000). "Das problemzentrierte Interview", Forum Qualitative Sozialforschung, 1. Available at: http://www.qualitative-research.net/index.php/fqs/article/view/\%201132/2519. 
60 Structural framework conditions and individual motivations for youth-mobility 